\title{
Os impactos da judicialização da saúde no município de São Paulo: gasto público e organização federativa'
}

\author{
Daniel Wei L. Wang \\ London School of Economics and Political Science \\ Natália Pires de Vasconcelos \\ Universidade de São Paulo \\ Vanessa Elias de Oliveira \\ Universidade Federal do $A B C$
}

Fernanda Vargas Terrazas

Conselho Nacional de Secretarias Municipais de Saúde

\begin{abstract}
Nos últimos anos constata-se no Brasil um aumento do número de decisões judiciais obrigando o poder público a fornecer medicamentos, insumos, equipamentos e cirurgias. Os juízes tendem a desconsiderar o impacto orçamentário de suas decisões e entendem que todos os entes da federação podem ser igualmente responsabilizados pelo fornecimento de qualquer item pedido pelo paciente. O presente estudo analisa o impacto dessas decisões para a gestão orçamentária da política de saúde no município de São Paulo por meio de uma estimativa de gastos com a judicialização para o ano de 2011 a partir dos dados disponibilizados pelo município e as publicações no Diário Oficial concernentes à compra de medicamentos e insumos sem licitação pela Secretaria Municipal de Saúde. De acordo com as estimativas do presente trabalho, o gasto do município com judicialização da saúde em 2011 é o equivalente a $6 \%$ do que o município gastou com sua política de assistência farmacêutica e 10\% do total gasto com fornecimento de medicamentos e material hospitalar, ambulatorial e odontológico. Além do mais, cerca de 55\% desse gasto são destinados ao fornecimento de medicamentos de responsabilidade de estados ou União, e por volta de 45\% para tratamentos não contemplados pelo Sistema Único de Saúde.
\end{abstract}

Palavras-chave: Judiciário; políticas de saúde; município de São Paulo; federalismo.

DOI: http://dx.doi.org/10.1590/0034-76121666

Artigo recebido em 31 jul. 2013 e aceito em 8 maio 2014.

${ }^{1}$ Os autores agradecem à Secretaria Municipal de Saúde do Município de São Paulo e em especial ao então secretário Januário Montone e ao doutor Roberto Siniscalchi pela entrevista concedida e pelos dados fornecidos. Agradecem também aos pareceristas da Revista de Administração Pública pelos comentários ao artigo. Os autores, claro, assumem total responsabilidade por eventuais erros. 
Los impactos de la judicialización de la salud en el municipio de São Paulo: gasto público y organización federativa

En los últimos años puede ser visto en Brasil un incremento en el número de decisiones judiciales obligando al Gobierno a proporcionar medicamentos, productos y procedimientos de salud. Los jueces normalmente ignoran el impacto presupuestario de sus decisiones y entienden que toda entidade federativa puede ser responsable para suministrar cualquier tratamiento solicitado por el paciente. Este estudio analiza el impacto de estas decisiones para la gestión del presupuesto de la política de salud en la Municipalidad de São Paulo. El gasto presupuestario fue calculado con información proveída por la Municipalidad de São Paulo y disponible en el Diario Oficial. Según las estimaciones del presente trabajo, el gasto del municipio con la judicialización de la salud en 2011 es equivalente a $6 \%$ del presupuesto de su política de asistencia farmacéutica y $10 \%$ del total gastado en el suministro de medicamentos y material hospitalar. Además, alrededor de 55\% de este gasto es para el suministro de medicamentos de la responsabilidad de los Estados o del Gobierno Federal y $45 \%$ para los tratamientos que no pertenecen a la política pública de salud.

Palabras clave: poder judicial; políticas de Salud; ciudad de Sao Paulo; federalismo.

The impacts of health care judicialization in the city of Sao Paulo: public expenditure and federal organization

During the last years, the number of judicial decision ordering the provision of health treatments, equipment and surgeries by the public health system has increased. Judges tend to ignore their decisions' budgetary impact and to consider that the Federal Government entities can be considered equally responsible by the supply of any item ordered by the patient. This paper analyzes the impact of these judicial decisions for the budgetary management of health policy in the City of Sao Paulo. It was considered an estimate with the expenses on the judicialization for the year of 2011, taking into consideration the data made available by the city and the publications in the official gazette about the acquisition of medications without bidding by the Municipal Health Department. According to the estimate of this article, the expenses of the city with health judicialization in 2011 is equivalent to $6 \%$ of the amount that the city spent with its policy of pharmaceutical assistance, and $10 \%$ of the total amount spent with the supply of medications, and hospital, dental and outpatient care material. Moreover, around 55\% of the total amount is spent with drugs supply which are responsibility from the states and the union, and around $45 \%$ is spent with treatments that are not included in the Unified Public System (known as SUS).

KEYWORDs: judiciary; health policies; city of São Paulo; federalism.

\section{Introdução}

Constata-se no Brasil um aumento do número de decisões judiciais obrigando o poder público a fornecer bens e serviços de saúde. Esse fenômeno é chamado por alguns de "judicialização da saúde". O Judiciário brasileiro tem sido muito receptivo a demandas individuais que pleiteiam a concessão de medicamentos, insumos e tratamentos de saúde pelo SUS. Sua posição mais frequente considera que o direito à saúde previsto na Constituição garante ao cidadão o direito de receber esses produtos sempre que houver a necessidade, por indicação médica, 
e a recusa de fornecimento pelo poder público. Na imensa maioria dos casos, os juízes obrigam os gestores de saúde a fornecer os produtos demandados pelos pacientes-requerentes, que pedem principalmente medicamentos (Ferraz, 2011; Ferreira et al., 2004; Wang, 2009). Levantamentos estatísticos apontam para uma taxa de sucesso do pleiteante contra o sistema público de saúde por volta de 85\% no Judiciário paulista (Ferreira et al., 2004; Wang et al., 2011; Wang e Ferraz, 2013).

O Judiciário brasileiro também tende a desconsiderar o impacto orçamentário de uma decisão judicial que obriga o sistema de saúde a fornecer um determinando tratamento. Para os juízes, em geral, questões relativas ao orçamento público, como a escassez de recursos e a não previsão de gasto, bem como o não pertencimento do medicamento pedido às listas de medicamentos do SUS, não são razões suficientes para se denegar o pedido de um tratamento médico, dado que este encontra respaldo no direito à saúde assegurado pela Constituição Federal.

Essa postura do Judiciário brasileiro permitiu - e até incentivou — o impressionante aumento no número de ações pleiteando tratamentos médicos com base no direito constitucional à saúde. $\mathrm{O}$ gasto do Ministério da Saúde com medicamentos cuja provisão foi determinada por ordem judicial passou de R 2,5 milhões em 2005 para aproximadamente $\mathrm{R} \$ 266$ milhões em 2011 (Advocacia-Geral da União e Ministério da Saúde, 2012). No mesmo período, o número de medicamentos fornecidos judicialmente pela Secretaria de Saúde do Estado de São Paulo (SES-SP) subiu de 799 para 14.563, um crescimento de 1.722,65\% em cinco anos (Wang, Terrazas e Chieffi, 2012). A estimativa mais recente do gasto da SES-SP com demandas judiciais calcula um gasto anual de cerca de $\mathrm{R} \$ 513$ milhões. Em termos comparativos, esse valor consistiria em $90 \%$ do gasto anual do SUS em diagnósticos em laboratórios clínicos no Estado de São Paulo (Naffah Filho, Chieffi e Correa, 2010).

Estes dados apontam de forma inequívoca dois fatos relevantes para os planejadores de políticas públicas e para a gestão do orçamento público: (1) existem cada vez mais ações contra o sistema público de saúde pedindo tratamentos médicos e (2) o impacto das decisões judiciais no orçamento público de saúde está longe de ser insignificante.

O impacto dessas decisões nos orçamentos da União e de alguns estados tem sido objeto de muitas pesquisas. Porém, salvo algumas exceções (Vieira e Zucchi, 2007; Leite et al., 2009; Machado et al., 2011), pouco se conhece sobre como decisões judiciais obrigando o fornecimento de bens e serviços de saúde — principalmente medicamentos — afetam os municípios.

Sabe-se, todavia, que as ações judiciais pedindo tratamentos e medicamentos têm afetado cada vez mais os orçamentos públicos municipais no Brasil. Em 2009, uma pesquisa envolvendo todas as secretarias municipais de saúde questionava-as sobre o impacto da judicialização em seu orçamento (Ferraz, 2011). No total, 1.276 municípios responderam, o que representou $24 \%$ do universo. Quando perguntados se há um crescente número de demandas judiciais pleiteando serviços e produtos de saúde, $34 \%$ dos municípios responderam que sim e que isso é um problema importante, $23 \%$ responderam que há crescimento de demanda, embora este não seja (ainda) um problema importante, e 46\% afirmaram que não enfrentavam, 
até então, esse problema. Com esses resultados é possível afirmar que, dentro dessa amostra, mais da metade dos municípios lida frequentemente com ações judiciais demandando do poder público tratamentos médicos e, ademais, um terço deles considera a judicialização da saúde um problema importante. Além disso, no primeiro semestre de 2009, o número de ações informadas pelos 1.276 municípios já era maior do que o total do ano inteiro de 2007 e próximo ao total de 2008. O mesmo fenômeno aconteceu em relação aos gastos com tais ações, sendo despendidos, até a metade de 2009, mais do que o total de 2007 e $78 \%$ do que foi gasto no ano inteiro de 2008. Os valores absolutos também não são desprezíveis, ainda mais quando se considera que eles correspondem ao gasto de apenas cerca de um quarto dos 5.560 municípios brasileiros (Ferraz, 2011).

Entretanto, os municípios possuem, em geral, orçamentos menores e infraestrutura menos desenvolvida que estados e União. Isso foi levado em consideração pela distribuição de competências dentro do Sistema Único de Saúde (SUS) que, em regra, atribuiu aos municípios ações e serviços de saúde de baixa ou média complexidade - a chamada "estrutura federativa do SUS", nos termos de Dourado e Elias (2011). Não obstante esse fato, é consolidado o entendimento no Judiciário brasileiro de que o paciente pode pleitear judicialmente bens e serviços de saúde a qualquer ente da federação — município, estado ou União — , independentemente da divisão de competências, das normas do SUS, ou do custo daquilo que se pede.

Este é também o entendimento do Supremo Tribunal Federal (STF), que o invoca sempre que um ente da federação alega não ser de sua responsabilidade, mas de outro ente, o que está sendo requerido judicialmente. Como exemplo desse posicionamento, há muito tempo consolidado no STF, observa-se o trecho transcrito:

A competência comum dos entes da federação para cuidar da saúde consta do art. 23, II, da Constituição. União, Estados, Distrito Federal e Municípios são responsáveis solidários pela saúde junto ao indivíduo e à coletividade e, dessa forma, são legitimados passivos nas demandas cuja causa de pedir é a negativa, pelo SUS (seja pelo gestor municipal, estadual ou federal), de prestações na área de saúde. (Suspensão de Liminar no 228, julg. 14/10/2008, publ. 21/10/2008)

Essa posição, determinando que em matéria de saúde pública a responsabilidade dos entes da Federação deve ser efetivamente solidária (todos podem responder por qualquer demanda judicial em matéria de saúde), encontra-se de tal forma consolidada que tramita no STF a proposta de se criar uma súmula vinculante (Proposta de Súmula Vinculante no 4) com o seguinte conteúdo:

responsabilidade solidária dos Entes Federativos no que concerne ao fornecimento de medicamento e tratamento médico ao carente, comprovada a necessidade do fármaco ou da intervenção médica, restando afastada, por outro lado, a alegação de ilegitimidade passiva corriqueira por parte das Pessoas Jurídicas de Direito Público.

A edição de uma súmula vinculante com esse conteúdo significaria vincular oficialmente os demais órgãos do Poder Judiciário e da administração pública direta e indireta, em 
quaisquer das esferas da federação, a esse entendimento (conforme 103-A da Constituição Federal), o que seria especialmente oneroso aos municípios. Estes se veem obrigados a fornecer tratamentos de altíssimo custo e complexidade que, de acordo com a divisão de competências do SUS, deveriam ser fornecidos pelos governos estaduais ou pelo Ministério da Saúde, os quais dispõem de recursos financeiros e previsão orçamentária para tanto.

O superintendente farmacêutico da prefeitura do Rio de Janeiro, ao ser entrevistado sobre a tese de que os entes da federação são solidariamente responsáveis para responder a pedidos judiciais, afirmou que "Esse problema da solidariedade pesa muito sobre o município porque recebemos pedidos de medicamentos caros que não são de nossa competência, mas chega a liminar com o 'cumpra-se' e nós ficamos de mãos atadas” (Vianna e Burgos, 2005).

Para exemplificar esta situação, o ex-secretário de Saúde do estado de São Paulo afirmou que, a depender do tratamento ordenado e do tamanho do orçamento de um município, já houve casos em que, para o cumprimento de apenas uma decisão judicial, o orçamento municipal em saúde foi comprometido em 20\% dos recursos previstos (Oliveira e Noronha, 2011). Dois exemplos que ilustram a afirmação do então secretário de Saúde são os municípios paulistas de Buritama e Campinas. No primeiro, mais da metade do orçamento de saúde é gasto para cumprimento de decisões judiciais e apenas um paciente conseguiu, via justiça, o acesso a um tratamento que custou 16\% do orçamento anual de saúde (Revista Época, 2012). No segundo, somente com atendimento de 86 novas ações recebidas em 2009, o município gastou quase $16 \%$ de todo seu orçamento para medicamentos (Advocacia-Geral da União e Ministério da Saúde, 2012).

Portanto, estudar como a judicialização da saúde afeta os municípios é importante porque o Judiciário, ao desconsiderar a divisão organizacional federativa do SUS estabelecida na Lei no 8.080/1990 e em outras normas do SUS, pode prejudicar o planejamento da gestão da saúde pelos entes federativos, que em muitos casos acabam atuando de maneira sobreposta (Sarmento e Telles, 2012). Além do mais, a judicialização tende a causar um grande impacto na política de saúde dos municípios que, em regra, possuem menor capacidade para lidar com os custos e a imprevisibilidade advinda dos gastos em saúde ordenados judicialmente. Diante desse cenário, este artigo pretende contribuir para o conhecimento nesse campo ao analisar o impacto da judicialização da saúde no município de São Paulo em termos de gasto público e de uma possível distorção da organização federativa do SUS a partir dos gastos impostos ao Executivo municipal pelo Judiciário.

\section{Método}

A escolha do município de São Paulo deu-se por dois motivos: i) o volume bastante grande de ações judiciais demandando bens e serviços de saúde, o que se deve principalmente ao fato de ser o município mais populoso do país e possuir um sistema público de saúde bem estruturado, dotado de uma ampla rede de serviços; ii) a existência de uma boa organização de dados disponibilizados publicamente pelo município, por meio das atas de registro de preço e de 
publicações no Diário Oficial, o que raramente acontece em municípios de menor dimensão. Portanto, em razão da importância do município de São Paulo e da viabilidade de se acessar os dados, foi feita a opção por se estudar esse caso.

Esta pesquisa busca contabilizar o gasto do município para cumprimento das ordens judiciais que determinam ao município de São Paulo o fornecimento de bens de saúde (medicamentos, insumos etc.) e analisar se e de que maneira esse gasto distorce a organização das competências dos entes dentro do SUS.

Para tanto, foi feita uma estimativa de gastos com a judicialização para o ano de 2011 tomando como fontes de análise: (1) dados disponibilizados pelo município de São Paulo (a) em seu sítio eletrônico e (b) por meio do Núcleo de Ação das Demandas Especiais (Demande); (2) publicações concernentes à compra de medicamentos e insumos sem licitação pela Secretaria Municipal de Saúde, constantes do Diário Oficial da Cidade de São Paulo, disponível para consulta on-line. Desta forma, considera-se que foi possível analisar todo o gasto com aquisição de bens de saúde para fins de cumprimento de decisão judicial.

(1a) Dados obtidos junto ao sítio eletrônico do Município de São Paulo

Dessa fonte foram colhidas as informações oficiais disponibilizadas pelo próprio município acerca de sua elaboração e execução orçamentária, mais especificamente, todas as informações concernentes ao orçamento da Secretaria Municipal de Saúde.

Além do próprio orçamento, foram sistematizadas todas as Atas de Registro de Preços válidas para 2011 provenientes de licitações firmadas entre o município e empresas farmacêuticas para a fixação de preços e termos de compra de insumos e medicamentos judicializados. Nesse caso, foram utilizadas as atas disponibilizadas pelo município em seu endereço eletrônico, bem como aquelas que, embora não constassem na página eletrônica, foram localizadas no Diário Oficial e tinham validade em 2011.

Como cada Ata de Registro de Preços traz consigo o preço licitado e a estimativa de consumo médio mensal para cada produto, para calcular o gasto anual multiplicou-se por 12 a quantidade mensal de cada produto licitado que a prefeitura espera ter de comprar, para a obtenção do consumo estimado anual. Esse resultado, multiplicado pelo preço acordado, redundou no gasto anual estimado para cada produto, conforme mostra a equação abaixo.

$$
\text { (Consumo médio mensal) } \times 12 \times(\text { preço acordado })=\text { gasto anual }
$$

(1b) Dados do Demande

Após entrevista com o gestor responsável pelo Núcleo de Ação das Demandas Especiais (Demande), órgão da Secretaria Municipal de Saúde responsável por centralizar e responder a todas as demandas contra a Secretaria, administrativas ou judiciais, obteve-se a lista de todos os medicamentos e insumos solicitados por via judicial em demandas ainda ativas, bem como a média de consumo mensal desses produtos, por demanda.

A obtenção dessa lista permitiu completar o levantamento de gastos, analisando também as Atas de Registro de Preços de medicamentos que, embora requeridos pela via judicial, já são fornecidos normalmente pela secretaria e, por isso, sua compra é feita por meio de 
atas regulares da Secretaria, firmadas para o atendimento de suas necessidades correntes, constando no sítio eletrônico apenas como "Atas - Medicamentos". Cada Ata de Registro de Preços, conformando o processo licitatório realizado anteriormente entre a municipalidade e a iniciativa privada, dispõe de informações sobre a média de consumo mensal geral dos medicamentos licitados, sem discriminar a quantidade a ser utilizada para cumprimento de decisões judiciais, e acorda preços para compras futuras.

Para calcular, a partir dessas atas, o gasto anual com esses produtos para fins de cumprimento de decisão judicial, foi utilizada a mesma equação empregada para as atas obtidas via página eletrônica da Secretaria Municipal de Saúde, com a única diferença de que, em vez de se usar os dados de consumo médio mensal informado nas Atas de Registro de Preços, usou-se o dado de consumo médio mensal desses produtos para atendimento de demandas judiciais informado pelo Demande.

(2) Dados obtidos junto ao Diário Oficial

A pesquisa empírica junto ao Diário Oficial do município foi realizada no início de 2012, o que permitiu mensurar quantas compras sem licitação para o cumprimento de ordens judiciais o município realizou em todo o ano de 2011, seja por dispensa de licitação, nos termos do artigo 24, inciso IV, da Lei no 8.666/1993, seja por inexigibilidade desta, nos termos do artigo 25, I, da mesma lei. Foram realizadas buscas no Diário Oficial da Cidade de São Paulo, por meio do mecanismo de busca avançada do sítio eletrônico. A pesquisa foi realizada com os seguintes termos: "cumprimento ordem judicial dispensa licitação".

Essa pesquisa, que excluiu aqueles medicamentos ou insumos para os quais há ata de registro de preço para sua compra, gerou um rol de 408 despachos (considerando aqui a compra de cada medicamento como uma ordem judicial) proferidos pela Secretaria Municipal de Saúde, determinando a compra de medicamentos e insumos e a respectiva emissão de nota de empenho, em razão do cumprimento de decisão judicial.

Diante destes despachos, foram catalogados os medicamentos comprados, os preços pagos e a dotação orçamentária da qual provieram os recursos para a compra, averiguando assim a origem dos recursos usados para cumprir essas decisões judiciais.

\section{Resultados}

Somando o valor das atas firmadas para o atendimento de demandas judiciais mais as outras atas que, embora não fossem exclusivamente feitas para atender demandas judiciais, tinham previstos gastos com judicialização, chegou-se ao valor de aproximadamente R \$ 7,2 milhões. Além dos tratamentos de saúde para os quais houve licitação, existem também aqueles comprados por dispensa de licitação. Conforme a metodologia acima explicitada, chegou-se ao valor de pouco mais de R \$ 1,5 milhão para esse tipo de compra de medicamentos. Assim, de acordo com a metodologia empregada, o gasto da Secretaria Municipal de Saúde com judicialização da saúde para o ano de 2011 foi estimado em aproximadamente R\$ 8,8 milhões (tabela 1). 


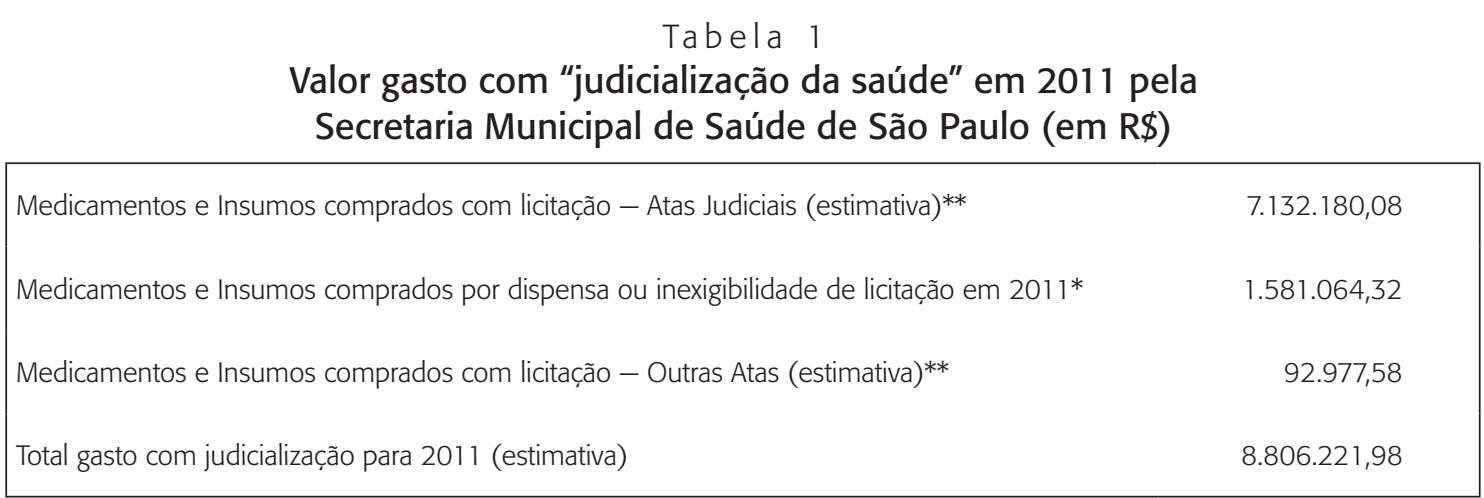

Fonte: Elaboração própria.

*Calculado a partir dos despachos autorizando a compra de medicamentos e insumos por ordem judicial com dispensa de licitação disponíveis no Diário Oficial em 2011.

** Calculado a partir do consumo médio mensal multiplicado pelo valor da unidade do produto e, posteriormente, multiplicado por 12 para se chegar ao valor anual estimado.

Para medir o quanto as ações judiciais distorcem a distribuição de competências do SUS, calculou-se quanto a Secretaria Municipal de Saúde de São Paulo gasta com medicamentos cujo fornecimento deveria ser de competência exclusiva de estados e/ou União de acordo com a política de assistência farmacêutica do SUS à época, quais sejam, os medicamentos do componente especializado da assistência farmacêutica dos grupos 1 e 2; e os medicamentos do componente estratégico da mesma política (Conass, 2007).

Além disso, observou-se um grande número de pedidos relacionados com insumos médicos, bem como a fórmulas alimentares. Quanto aos insumos, é importante esclarecer que, excetuando aqueles utilizados para controle da glicemia (tiras reagentes e lancetas) e para a aplicação de insulina (seringas), que têm o seu fornecimento garantido pela Lei no $11.347 / 2006$, os demais não são fornecidos como produtos, mas estão incluídos em procedimentos hospitalares, ambulatoriais ou na atenção domiciliar. Desse modo, salvo as exceções mencionadas, o SUS não fornece nenhum insumo isoladamente, tal como faz com os medicamentos.

Da mesma forma, em regra, o SUS não fornece fórmulas alimentares. No entanto, no estado de São Paulo, onde está localizado o município objeto de nosso estudo, há um protocolo da Secretaria Estadual de Saúde para fornecimento de fórmulas infantis especiais para pacientes com alergia à proteína do leite de vaca (Resolução SS-336/2007). Assim, nesse estado, esse tipo específico de fórmula, que é o mais comumente solicitado, é ofertado pelo SUS. Os demais tipos de fórmulas alimentares não o são.

Dito isso, o resultado mostra que por volta de $55 \%(\mathrm{R} \$ 4.856 .794,85)$ dos recursos gastos pelo município para cumprir decisões judiciais servem ao fornecimento de medicamentos e insumos que fazem parte das listas da União e dos estados. Desse valor, R\$ 3.890.219,04 são gastos em medicamentos e insumos adquiridos por meio de licitação (com Ata de Registro de Preço) para atender ações judiciais, o que indica que o município já prevê que terá de fornecer produtos que são da competência de outro ente (tabela 2). Ou seja, mais da metade dos gastos 
municipais com demandas judiciais refere-se a itens que são de responsabilidade dos demais entes federados, dentro da lógica federativa do SUS.

Tabela 2

Valor gasto com medicamentos e insumos de competência de outros entes pela Secretaria Municipal de Saúde de São Paulo (em R\$)

\begin{tabular}{|lrrr|}
\hline & Medicamento & \multicolumn{1}{c|}{ Insumo } & \multicolumn{1}{c|}{ Total } \\
\hline Com licitação & $999.964,80$ & $2.890 .254,24$ & $3.890 .219,04$ \\
Sem licitação & $34.695,12$ & $931.880,69$ & $966.575,81$ \\
Total & $1.034 .659,92$ & $3.822 .134,93$ & $4.856 .794,85$ \\
\hline
\end{tabular}

Fonte: Elaboração própria

Também merece atenção o fato de que, quando se subtrai do gasto total o valor gasto com medicamentos de responsabilidade de União e estados (55\%) e com aquilo que já faz parte da responsabilidade dos municípios e que foi adquirido por meio de Atas não exclusivas para cumprimento de ações judiciais, que representa $0,01 \%$ do total de gastos $(\mathrm{R} \$ 92.977,58)$, tem-se como resultado que aproximadamente $45 \%$ do gasto com judicialização no município de São Paulo são destinados à compra de produtos que não estão incluídos nas listas do SUS, ou seja, estão fora da política pública de saúde para acesso universal.

Em face do impacto da judicialização, a Secretaria Municipal de Saúde de São Paulo tentou se precaver contra os impactos das decisões judiciais. Para tanto, criou em março de 2010 um órgão específico, o Núcleo de Ação das Demandas Especiais (Demande), que centraliza todas as ações judiciais contra a Secretaria que solicitam o fornecimento de medicamentos, insumos e tratamentos médicos. O Demande também realiza licitações para aqueles produtos que a Secretaria espera ter de fornecer por ordem judicial, antecipando e racionalizando, assim, o gasto.

As "licitações preventivas" diminuem os custos porque se abre uma concorrência por meio da qual diferentes indústrias competem para oferecer o menor preço. Ademais, todas elas são obrigadas a fornecer o medicamento com descontos de $25 \%$, de acordo com a Resolução no 4, de 2006, da Câmara de Regulação do Mercado de Medicamentos (CMED). Pelos dados levantados neste trabalho, apenas 17,9\% (R\$ 1.581.064,32) do gasto da SMS-SP para cumprir decisões judiciais em 2011 foram para adquirir medicamentos sem licitação. Isso indica que grande parte do gasto com judicialização já estava prevista pelo município.

Conforme pesquisa realizada junto ao site do Tribunal de Justiça do Estado de São Paulo, apenas com decisões proferidas no ano de 2010 contra o município de São Paulo, envolvendo o fornecimento de tratamentos de saúde, observou-se que para os 11 medicamentos mais demandados judicialmente no período houve licitação e posterior ata de registro de preço (tabela 3). 


\section{Tabela 3}

Ranking de produtos mais judicializados contra o município de São Paulo em 2010

\begin{tabular}{|lc|}
\hline Produto & Número de ações \\
\hline Tira reagente & 30 \\
Lanceta & 26 \\
Insulina Glargina (Lantus) & 25 \\
Agulhas para caneta de insulina & 21 \\
Glicosímetro & 18 \\
Insulina Lispro (Humalog) & 18 \\
Insulina Aspart & 14 \\
Bomba de infusão de insulina & 13 \\
Fraldas descartáveis & 13 \\
Insulina Detemir (Levemir) & 8 \\
Insulina NPH & 8 \\
\hline
\end{tabular}

Fonte: Elaboração própria com base em pesquisa no site do Tribunal de Justiça de São Paulo.

\section{Discussão}

A relevância do gasto com judicialização no município de São Paulo era esperada, considerando os dados disponíveis sobre o fenômeno em estados e União (Advocacia-Geral da União e Ministério da Saúde, 2012; Naffah Filho, Chieffi e Correa, 2010; Biehl et al., 2010; Santos, 2006). Esse fato, entretanto, não havia sido anteriormente comprovado. A presente pesquisa demonstrou que, de fato, uma parcela significativa dos recursos da política de assistência farmacêutica e de distribuição de outros materiais em saúde está sendo determinada e realocada judicialmente. Ao se considerar que o gasto total estimado para cumprimento de ordens judiciais obrigando fornecimento de medicamentos e insumos de saúde - incluindo compras com e sem licitação — foi de mais de R\$ 8,8 milhões, tem-se que o gasto com judicialização da saúde representa mais de $10 \%$ do total liquidado em 2011 na compra de medicamentos (dotação 18.4107 - Administração do Material Hospitalar, Ambulatorial e Odontológico), ou mesmo 6\% do que despendeu o município com sua política de assistência farmacêutica (dotação 18.4106 — Implementação e Manutenção da Assistência Farmacêutica e Remédio em Casa).

O dado de que o município recebe ordens judiciais para adquirir medicamentos e insumos não contemplados pelas listas do SUS é coerente com o resultado de outros trabalhos 
que estudaram a judicialização da saúde (Wang, 2013; Wang et al., 2012; Machado et al., 2011; Vieira e Zucchi, 2007). Importa ressaltar que o fato de um tratamento pertencer à política não significa que ele deveria ser fornecido ao paciente, uma vez que para ter acesso ao tratamento é preciso também observar os protocolos clínicos e as diretrizes terapêuticas, nos termos do que dispõe a Lei no 8.080/90 em seu capítulo sobre a assistência terapêutica e a incorporação de tecnologia em saúde (incluído recentemente pela Lei 12.401/11) e o Decreto 7.508/11.

O dado mais surpreendente é que a maior parte do gasto judicializado do município de São Paulo é direcionada à aquisição de medicamentos e insumos cujo fornecimento são da competência de outro ente. Isso reforça a premissa deste artigo de que a judicialização da saúde nos municípios possui características particulares que afetam a organização federativa do SUS e que precisam ser mais bem compreendidas.

O Judiciário, ao adotar as teses de que há responsabilidade solidária dos entes da federação para compor o polo passivo de ações demandando bens e serviços de saúde e de que o acesso a bens de saúde não se restringe àquilo que foi previamente definido em listas públicas, parece estar, indiretamente, redesenhando a política de assistência farmacêutica do SUS no que tange à distribuição de competências entre os entes federados.

Os efeitos para o sistema são deletérios, por pelo menos três motivos: i) porque acarretam um acesso desigual ao SUS, pois aqueles que litigam têm acesso a um rol mais amplo de ações e serviços de saúde, enquanto o restante da população conta apenas com aquilo que está definido nas políticas; ii) porque geram um desequilíbrio na distribuição de competências dentro do sistema, sobrecarregando o ente mais frágil do conjunto, o município; e iii) por fim, porque geram um elevado grau de incerteza ao gestor público, não apenas sobre quanto recurso público precisará disponibilizar para a compra de medicamentos demandados judicialmente, mas também sobre o impacto nas contas públicas e os cortes necessários em outras despesas e políticas.

A realização de licitações para a compra dos produtos mais judicializados demonstra que as ações judiciais fazem parte da rotina da gestão pública da saúde, condicionando a ação do gestor, que se antecipa à própria decisão judicial e realiza licitações para os produtos mais pedidos, sabendo de antemão que provavelmente será obrigado judicialmente a fornecê-los. O Judiciário obriga a Secretaria, dessa forma, a arraigar o acesso desigual ao SUS, uma vez que existem produtos já licitados, mas acessíveis àqueles que recorreram à via judicial.

Com relação aos produtos de responsabilidade de outros entes, mas cujo fornecimento foi ordenado ao município, importa ressaltar que o município em estudo tem um dos maiores orçamentos do país. No entanto, os demais municípios brasileiros possuem menor capacidade financeira para lidar com a imprevisibilidade advinda dos gastos em saúde ordenados judicialmente, uma vez que os recursos totais disponíveis para remanejamento ao cumprimento dessas decisões também tendem a ser de menor monta.

A partir desta premissa, pode-se dizer que a judicialização da saúde tem o potencial de gerar custos inesperados às diferentes esferas de governo da federação. Esses custos são 
também regressivos, ou seja, pesam mais sobre os entes federados a rigor mais pobres: os municípios e, dentre eles, aqueles menores e mais carentes.

A Constituição de 1988 caracterizou-se por preceituar uma ampla descentralização de competências legislativas, fiscais e administrativas (Silva, 2011), transferindo aos estados e municípios a responsabilidade pela implementação de uma série de políticas públicas. Nesse cenário, a política de saúde foi a que mais rapidamente se desenvolveu, em termos de institucionalização e concretização da descentralização proposta em 1988, por uma série de fatores, salientando-se, dentre outros: força e capilaridade do movimento sanitário, importância desse grupo nos debates da Assembleia Constituinte, capacidade de indução do Ministério da Saúde (Arretche, 2000).

Tal desenvolvimento não significou apenas a transferência de responsabilidade e recursos para estados e municípios, mas, mormente, a constituição de um sólido "sistema" de gestão da política de saúde que leva em consideração a estrutura federativa brasileira e o impacto dessa para a gestão das políticas públicas (Dourado e Elias, 2011).

A organização federativa da política de saúde tem paralelo com a noção de divisão de competências entre níveis de governo na federação, princípio esse estendido para a gestão do SUS: União, estados e municípios devem não apenas "cooperar", como prevê a decisão do STF anteriormente citada, mas, mais do que isso, dividir competências, conforme as capacidades financeiras e técnicas de cada esfera de governo. De fato, a cooperação é um dos princípios estruturantes das federações, mas não o único. Dizer que a gestão é compartilhada e que deve haver cooperação não significa que todos os entes devem igualmente ser responsabilizados pela disponibilização de tratamentos e serviços dos mais variados níveis de complexidade.

O que vale salientar, quando se analisam as políticas públicas e a divisão de competências em sistemas federativos, é o fato de que cooperação não significa corresponsabilização. O SUS, sendo um "sistema", funciona - ou deveria funcionar - como tal, com cada órgão desempenhando um papel para o seu adequado funcionamento e manutenção. Por isso, não há razão para supor que todos os entes federados são igualmente responsáveis pela assistência farmacêutica, assim como não são igualmente responsáveis por transplantes de órgãos, por exemplo.

A estrutura federativa é um aspecto importante quando se analisa as políticas públicas e, de fato, ser ou não uma federação importa na compreensão da divisão de competências entre níveis de governo. O federalismo é composto por autonomia, cooperação, compartilhamento e até competição.

Não dá para imaginar que haverá - ou que deve haver - corresponsabilização na gestão de todas as políticas públicas, em todos os seus aspectos. A divisão de competências é profícua e eficaz para o processo de implementação das políticas governamentais e, se por um lado dificulta o entendimento da população acerca de a quem compete a responsabilidade sobre os diferentes componentes das políticas, por outro possibilita que essa responsabilidade seja dividida com base nas capacidades de cada esfera de governo, que são distintas não apenas em termos financeiros, mas também em termos de planejamento e de recursos humanos para a implementação dessas políticas. 
No caso da Política de Assistência Farmacêutica no SUS, a mais afetada pelo fenômeno da judicialização da saúde, a importância da organização federativa fica bastante clara. Em linhas gerais, municípios são responsáveis pela assistência farmacêutica básica, os estados e a União pelos medicamentos especializados e esta última pelo fornecimento dos medicamentos estratégicos (Conass, 2007).

Isso não significa que, quando capazes de assumir a gestão de níveis mais complexos de atenção, os municípios não possam fazê-lo (Decreto no 7.508/2011); é o que acontece com grande parte dos municípios de maior porte, capitais ou mesmo polos regionais. Estados e municípios podem assumir serviços e disponibilizar tratamentos e insumos mais complexos e/ ou caros, desde que possam assumir essa responsabilidade.

Houve, portanto, uma preocupação em se organizar o SUS de forma a, em regra, atribuir as políticas de saúde que demandem mais recursos e melhor infraestrutura para os entes com maior capacidade de provê-las, quais sejam, os estados e o governo federal. Por essa razão é que se pode afirmar que as decisões judiciais que tratam todos os entes federados, União, estados e municípios, como igualmente responsáveis pela assistência farmacêutica são deletérias para o sistema de saúde porque desarranjam sua organização federativa de forma a onerar excessivamente os municípios, que podem ver seus recursos comprometidos com poucas ações judiciais - ou até mesmo uma única, conforme citado por Oliveira e Noronha (2011).

\section{Conclusão}

O presente trabalho teve por objetivo mostrar que o tema da judicialização da saúde tem se tornado cada vez mais relevante para os municípios e para a gestão municipal de políticas públicas, colocando aos gestores públicos o desafio de lidar com os gastos (muitas vezes imprevistos) gerados pelo cumprimento de decisões judiciais dentro de um contexto de orçamentos limitados. Também foi discutido como a judicialização, ao não respeitar a lógica que permeia a organização federativa do SUS, pode redundar aos municípios um ônus orçamentário maior do que muitos deles podem suportar.

Conforme evidenciado no estudo de caso sobre o município de São Paulo, o volume de gastos que deve ser realocado para o cumprimento dessas decisões tem se mostrado significativo. Estimou-se que o gasto total da judicialização em 2011 representa 6\% do que o município gastou nesse ano com sua política farmacêutica e $10 \%$ do orçamento para fornecimento de medicamentos e material hospitalar, ambulatorial e odontológico. Além do mais, cerca de $55 \%$ do gasto com judicialização da saúde são destinados ao fornecimento de medicamentos de responsabilidade de estados ou União, distorcendo a organização federativa do sistema, e $45 \%$ para tratamentos não contemplados pelo SUS.

Dessa maneira, os dados apontam para os seguintes impactos da judicialização: a criação de um acesso desigual ao SUS, favorecendo sobremaneira aqueles que acionam o Judiciá- 
rio; um desequilíbrio na distribuição de competências dentro do sistema, que potencialmente sobrecarrega o município; e a dificuldade para o planejamento e a gestão do orçamento público dada a imprevisibilidade do gasto imposto pelas ações judiciais.

Importa ressaltar que São Paulo, por ser o mais rico município da federação, talvez tenha condições mais propícias para absorver o impacto orçamentário gerado pelas decisões judiciais. Municípios menores podem não ter — e, em geral, não têm - essa capacidade, especialmente por contarem com menos recursos disponíveis para cumprir as decisões, com ou sem licitação do medicamento litigado, sem comprometer outras ações e serviços da política pública de saúde. Se o quadro encontrado em São Paulo já suscita preocupações, a situação em outros municípios pode apontar casos ainda mais graves.

Futuras pesquisas focadas em municípios menores, bem como estudos que analisem comparativamente o funcionamento e a suficiência de mecanismos para reorganizar o desenho federativo distorcido pelas ações judiciais ${ }^{2}$ certamente serão relevantes para completar o quadro que o presente artigo começou a desenhar e ampliar o entendimento acerca dos efeitos diversos gerados pelos processos de judicialização da saúde.

\section{Referências}

ADVOCACIA-GERAL DA UNIÃO; MINISTÉRIO DA SAUUDE. Intervenção Judicial na saúde pública: panorama no âmbito da Justiça Federal e apontamentos na seara das justiças estaduais. Brasília, 2012.

ARRETCHE, Marta. Estado federativo e políticas sociais: determinantes da descentralização. Rio de Janeiro: Revan, 2000.

BIEHL, João et al. Judicialization of the right to health in Brazil. The Lancet, v. 373, n. 9682, p. 2182-2184, jun. 2010.

CONASS. Assistência farmacêutica no SUS. Brasília: Conass, 2007.

DOURADO, Daniel de A.; ELIAS, Paulo E. Regionalization and political dynamics of Brazilian health federalism. Revista de Saúde Pública, v. 45, n. 1, p. 204-211, fev. 2011.

FERRAZ, Octávio M. Brazil. Health inequalities, rights and courts: the social impact of the judicialization of health. In: YAMIN, Alicia; GLOPPEN, Siri (Org.). Litigating the right to health. Cambridge: Harvard University Press, 2011. p. 76-102.

FERREIRA, Camila D. et al. O Judiciário e as políticas de saúde no Brasil: o caso Aids. Monografia vencedora do Concurso de Monografias "Prêmio IPEA 40 anos", 2004.

\footnotetext{
${ }^{2}$ Em ações em que o governo federal é processado juntamente com estados ou municípios, e o paciente é atendido pelo serviço estadual ou municipal, o governo federal repassa a estados ou municípios parcela do valor do medicamento/tratamento. Em 2011, foram repassados por volta de R\$ 22 milhões (Advocacia-Geral da União e Ministério da Saúde, 2012).
} 
LEITE, Nair L. et al. Ações judiciais e demandas administrativas na garantia do direito de acesso a medicamentos em Florianópolis-SC. Revista de Direito Sanitário, v. 10, n. 2, p. 13-28, jul./out. 2009.

MACHADO, Marina A. et al. Judicialização do acesso a medicamentos no estado de Minas Gerais, Brasil. Revista de Saúde Pública, v. 45, n. 3, p. 590-598, jun. 2011.

NAFFAH FILHO, Michel; CHIEFFI, Ana C.; CORREA, Maria C. S-Codes: um novo sistema de informações sobre ações judiciais da Secretaria de Estado da Saúde de São Paulo. Bepa, v. 7, n. 84, p. 18-30, 2010.

OLIVEIRA, Vanessa E.; NORONHA, Lincoln. Judiciary-Executive relations in policy making: the case of drug distribution in the state of São Paulo. Brazilian Political Science Review, v. 5, n. 2, p. 10-38, 2011.

REVISTA ÉPOCA. O paciente de $R \$ 800$ mil. 16 mar. 2012. Disponível em: <http://revistaepoca. globo.com/tempo/noticia/2012/03/o-paciente-de-r-800-mil.html>.

SANTOS, Carla Carlos. Estratégias para reorganização e otimização das atividades destinadas ao fornecimento de medicamentos demandados judicialmente contra a Secretaria de Estado de Saúde do Distrito Federal. Dissertação (mestrado) - Escola de Ciências da Saúde, Universidade de Brasília, Brasília, 2006.

SARMENTO, Daniel; TELLES, Cristina. Judicialização da saúde e responsabilidade federativa: solidariedade ou subsidiariedade? In: ASENSI, Felipe; PINHEIRO, Roseni (Org.). Direito sanitário. Rio de Janeiro: Elsevier, 2012. p. 117-129.

SILVA, Virgílio Afonso. Federalismo e articulação de competências no Brasil. In: PETERS, Guy; PIERRE, Jon (Org.). Administração pública: coletânea. Brasília: Editora Unesp; Enap, 2011.

VIANNA, Luis W.; BURGOS, Marcelo B. Entre princípios e regras: cinco estudos de caso de ações civis públicas. Dados — Revista de Ciências Sociais, v. 48, n. 4, p. 777-843, out./dez. 2005.

VIEIRA, Fabíola; ZUCCHI, Paola. Distorções causadas pelas ações judiciais à política de medicamentos no Brasil. Revista de Saúde Pública, v. 41, n. 2, p. 214-222, abr. 2007.

WANG, Daniel. Courts as healthcare policy-makers: the problem, the responses to the problem and problems in the responses. Direito GV Research Paper Series N. 75, 2013. Disponível em: <http:// ssrn.com/abstract=2335145> ou <http://dx.doi.org/10.2139/ssrn.2335145>.

WANG, Daniel. Poder Judiciário e políticas públicas de saúde: participação democrática e equidade. Cadernos Gestão Pública e Cidadania, v. 14, n. 54, p. 51-87, jan./jun. 2009.

WANG, Daniel et al. Judiciário e fornecimento de insulinas análogas pelo Sistema Público de Saúde: direitos, ciência e política pública. Relatório de pesquisa do Projeto Casoteca Direito GV, 2011.

WANG, Daniel; FERRAZ, Octavio. Reaching out to the needy? Access to justice and public attorneys' role in right to health litigation in the city of Sao Paulo. SUR International Journal on Human Rights, v. 10, n. 18, p. 158-179, jun. 2013. 
WANG, Daniel; TERRAZAS, Fernanda; CHIEFFI, Ana. Public system responses to health litigation: the case of the state of Sao Paulo Secretary of Health. In: ANNUAL MEETING OF THE LAW AND SOCIETY ASSOCIATION, 2012, Honolulu.

Daniel Wei L. Wang é doutor em direito pela London School of Economics and Political Science (LSE). Faz pós-doutorado e leciona direitos humanos na London School of Economics and Political Science (LSE).E-mail: d.w.wang@lse.ac.uk.

Natália Pires de Vasconcelos é mestranda em direito constitucional na Universidade de São Paulo. Pesquisadora da Sociedade Brasileira de Direito Público (SBDP) e do Núcleo de Estudos Comparados e Internacionais (Neci-USP). E-mail: natalia.vasconcelos@usp.br.

Vanessa Elias de Oliveira é doutora em ciência política pela Universidade de São Paulo (USP) e professora adjunta do Bacharelado e da Pós-Graduação em Políticas Públicas da Universidade Federal do ABC (UFABC). E-mail: vanessa.oliveira@ufabc.edu.br.

Fernanda Vargas Terrazas é mestre em direito do Estado pela Universidade de São Paulo (USP). Assessora do Conselho Nacional de Secretarias Municipais de Saúde (Conasems). E-mail: fernanda@conasems. org.br. 